\title{
Weather Prediction in India
}

\begin{abstract}
A SYMPOSIUM on weather prediction was held $A$ at Poona on July 25-26 under the auspices of the National Institute of Sciences of India. The problem was discussed in its various aspects, namely, seasonal forecasting in India, air-mass analysis and short-period weather forecasting with special reference to the forecasting of nor'-westers in Bengal, use of upper air data in weather forecasts, latent instability in the atmosphere and its consequences, rainfall due to western disturbances and the associated upper air temperatures, weather forecasting for aviation with special reference to local forecasts and kinematical methods in weather forecasting.
\end{abstract}

The president, Prof. M. N. Saha, in his opening remarks, referred to the development of synoptic charts in India from the time of Blanford and Eliot, and to the many new methods in the art of weather prediction introduced in India. Dr. C. B. Normand reviewed the complexities of the problem which the meteorologists have to face. At one time the practical forecaster could devote most of his time to con. sideration of rainfall. Now airmen want forecasts of upper winds, of height of cloud, of fog, duststorms, sudden squalls. There is this variety of requirements, and yet the decisions of the forecaster have to be made quickly ; there is no opportunity for lengthy calculation. A hopeful method of analysisone which is now a live issue among meteorologistsis to focus attention on the identification of air masses and to picture how the different homogeneous air masses should interact at their boundaries and behave within themselves. India is the country in which the subject of seasonal forecasting has been most intensively studied, and yet the utmost one can do at present is to give a very general indication of total rainfall over a large area for a period of 2-4 months. The proper assessment of success in weather forecasting is not so easy as one would imagine at first sight. Every forecaster-amateur, professional or quack-finds some of his forecasts turning out correctly, if he forecasts often enough and yet it is a curious fact, as pointed out by Sir Gilbert Walker some years ago, that "while the forecasting efforts of a charlatan are judged by their occasional successes, it is the occasional failures of a Government department which are remembered".

The first forecast of the monsoon rain, which was mainly based on the snowfall on the Himalayas and the Suleman range during the preceding January to May, was issued by Blanford in 1886. Gradually Eliot added other factors, the south-east trades at Mauritius, Zanzibar and Seychelles, data from South Australia and Cape Colony, and 'Nile flood'. His method involved interpretations that were liable to personal bias. The first forecast using a regression equation was made in 1909 by Walker. In 1924, Walker worked out six formulæ for forecasting rains in the Peninsula, north-east India and north-west India, in which use was made of twenty-eight factors selected out of a large number after applying his statistical test. To these, Field proposed the addition of a factor of special interest, as it indicated the way to a new source of seasonal indicators, namely, the upper winds and the upper air; his prognostic factor for the winter rains over northern India is the upper wind of the autumn over Agra. The re-examination of the data in recent years, and the application of various statistical tests, have revealed a diminution of the significance of some of the factors. Nevertheless, the total correlation coefficient is still 0.63 for the total monsoon rain of the Peninsula and $\mathbf{0 . 6 4}$ for that of north-west India and 0.72 for the winter rain of north-west India. In presenting the above review of seasonal forecasting in India, Dr. S. R. Savur said that the methods of correlation are strictly applicable only when all the quantities correlated are distributed normally. To overcome this defect, general methods are being developed. The theory, however, is still in its infancy.

The method of forecasts for ten-day periods developed by Franz Baur, of the German Meteorological Service, which rests on a combination of statistics and synoptics, as well as the 'composite-map method' of forecasts developed by Multanovsky and his collaborators, in which the time interval for the fore. cast is determined by the period which marks the type of the synoptic process involved, were explained by Mr. S. Basu from the point of view of their possible application to Indian conditions.

Air mass analysis received a good deal of attention. Dr. S. N. Sen explained the methods adopted in India for the identification of the different air masses ; these are, broadly speaking, of two classes, oceanic and continental, but it is possible to divide them into several sub-classes. He showed certain types of stationary fronts which often develop over the Indian area.

A great help in identifying the different air masses is the drawing of stream-lines and trajectories of air at different levels deduced from pilot balloon and cloud movements, a method which is now in daily use. Information about upper air temperatures and humidities whenever available helps to make the identification more certain. Dr. K. R. Ramanathan explained how 'warm fronts' somewhat similar to those met with in European latitudes are associated with depressions and storms in the Bay of Bengal. The two air masses between which the front forms in the Bay of Bengal are the dry, cold air from north India and the moist equatorial air from the south Bay of Bengal. A modified type of 'front' or partition zone is associated with storms of the pre-monsoon season. Monsoon depressions tend to form on the zone between fresh monsoon air and old monsoon air, the former behaving as a cold mass and the latter as a warm mass. Dr. S. K. Pramanik gave an application of air mass analysis to the problem of forecasting nor'-westers in Bengal, and Mr. S. $\mathbf{P}$. Venkiteswaran discussed certain relationships between upper air temperatures over Agra and distribution of rainfall during passage of western disturbances.

The role of latent instability in the atmosphere in the development of thunderstorms, dust storms, etc., formed the subject of an interesting communication by Dr. N. K. Sur. This term (defined by Normand in NATURE of October 3,1931, p. 583) refers to a certain thermodynamical state of the atmosphere in which, in suitable circumstances, an expenditure of a small amount of energy leads to a release of a large 
amount of energy. Absence of latent instability is associated with dry fine weather with occasional high clouds of non-convectional type, and its existence usually with convective types of clouds like cumulus or cumulo-nimbus or with dust or thunderstorms.

Mr. Krishna Rao discussed the problems which arise in weather forecasting for aviation, which can be classified into three categories, regional, route and local. In forecasting radiation ground fog, the "Taylor diagram' has not proved very useful in India except that it can be used to rule out days when fog is unlikely. Daily tephigrams based on aeroplane soundings constitute the most valuable items in forecasting convectional phenomena, formation, clearing or persistence of clouds.

The kinematical methods in weather forecasting developed by Dedebant and Pettersen also received attention. Whenever any pressure system, such as a cyclone, an anticyclone, a trough or a front, is in continuous motion, one can, from a knowledge of the changes that have taken place in the system in the previous two or three hours, calculate the velocity and acceleration of each point of the system and thus determine the position as well as the configuration of the system during the next 6 or 12 hours. The deepening or filling of pressure over an area bounded by two closed isobars is equal to the planimetric value of the barometric tendency within the same area. Dr. S. K. Banerji gave an application of these and other kinematical laws to certain Indian storms, particularly to explain the curvature of their tracks.

In winding up the discussion, Dr. Normand referred to the future of weather forecasting. He said that it seems doubtful whether the statistical methods applied to surface data will result in any appreciable improvement of seasonal forecasting. The region where we have to look for the improvement of forecasts of all kinds from short to long range is the upper air. More data by aeroplanes, radio sondes and balloon meteorographs are needed both in dayto-day analysis of the weather situation and in the search for factors of use in seasonal forecasting.

\section{Engineering Research and Soil Corrosion}

$\mathrm{I}^{\mathrm{N}}$ February 1935, the Council of the Institution of Civil Engineers adopted a more active policy in regard to engineering research and constituted a Research Committee with wide terms of reference. Previously, specific problems had been investigated by committees appointed specially for each case, and their work produced results of great importance. The growth in scientific knowledge and in the size and complexity of the problems confronting the engineer, and also the great changes which have been effected in the materials with which he has to work, brought about a realization of the necessity for greater understanding of the scientific basis of engineering practice. The Committee was entrusted with the duties of making recommendations of subjects for research and investigation, and of maintaining contact with other bodies engaged in similar work. While it has mainly limited its activities to problems in branches of engineering not ordinarily included in the programmes of the more specialized institutions, it has actively co-operated with many of these in researches of common interest.

The report of the Committee for the years 1935-36 and 1936-37 has now been issued ${ }^{1}$. The general policy has been to make use of the existing research organizations such as those of the Department of Scientific and Industrial Research, and of the universities and technical colleges, and no attempt has been made to set up an independent laboratory. The researches in which the Committee is in this way taking part are classified under the general headings : materials, soil mechanics, hydraulics, structures, and specialized engineering practiceand it will be of interest to those engaged in other branches of science to learn of the inclusion of such subjects of investigation as the most desirable types of fish-passes in rivers and the practice to be prescribed for the use of self-contained breathing apparatus in sewers and other engineering works. None of the investigations has as yet been completed but, from time to time, in the Journal of the Institution, in the proceedings of other societies and in the technical press, reports of progress or of partial results have been published.

Part 2 of the report gives detailed accounts of the progress of the researches undertaken. One of these deals with "Soil Corrosion of Metals and Cement Products". The increasing occurrence of reports of severe corrosion of concrete in clay soils containing sulphate salts has shown the need for more information than is at present available as to the conditions which are potentially dangerous and as to the most effective protective measures. After a questionnaire had been circulated to engineers throughout Great Britain inquiring into the prevalence of corrosion and the type of soil in which it was found, it became evident that the research ought to be organized on a wider basis, and a new committee was formed to include members from the Iron and Steel Institute, the British Non-Ferrous Metals Research Association, the National Physical Laboratory, the Building Research Station and the Rothamsted Experimental Station. Considerable financial support is being given by manufacturers and organizations interested in cement and concrete, and a scheme of research extending over ten years has been envisaged.

From a study of the work already recorded, it has been made evident that the corrosion of metals is far more dependent upon the nature of the soil, its composition and physical condition in respect of perviousness, moisture-content, etc., than upon any variations in type of ferrous metal or in the state of a non-ferrous metal. A necessary preliminary to the consideration of tests on various metals is therefore the decision to concentrate attention on conditions of environment, for which purpose a special subcommittee has been formed.

A separate research on the subject of "Vibrated Concrete" has yielded several interesting results. From the work so far carried out, it appears that the properties of vibrated concrete are merely those of a concrete in which satisfactory consolidation has been obtained with mixes which are drier than those associated with hand-compacting. The method thus 